\title{
Physicochemical data of the Belgian River Meuse from 1972 to 2010
}

Adrien Latli, DG03 Service Public de Wallonie, Patrick Kestemont, RIWA \& CIM-Meuse
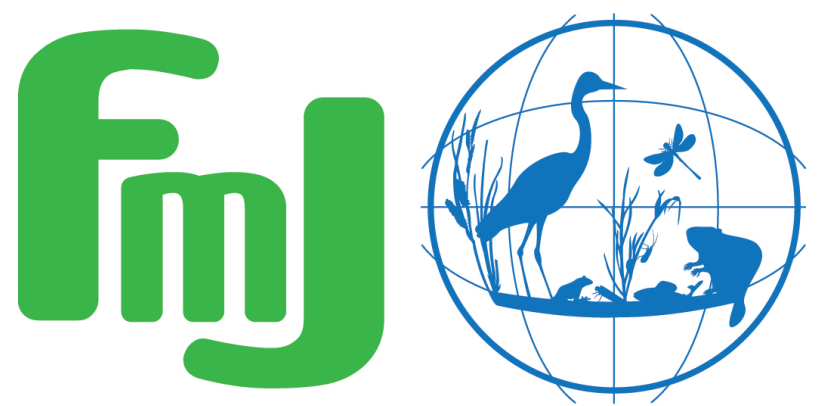

Freshwater Metadata Journal 



\section{Physicochemical data of the Belgian River Meuse from 1972 to 2010}

Adrien Latli ${ }^{1}$, DG03 Service Public de Wallonie ${ }^{2}$, Patrick Kestemont ${ }^{1}$, RIWA $^{3}$ \& CIM-Meuse ${ }^{4}$

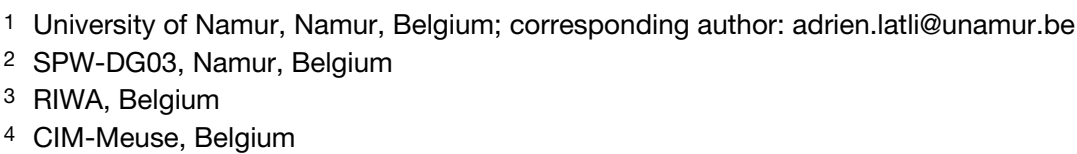

Please cite this paper as follows: Latli, A., Service Public de Wallonie, Kestemont, P., RIWA \& CIM-Meuse, 2018. Physicochemical data of the Belgian River Meuse from 1972 to 2010. Freshwater Metadata Journal 32: 1-5. https://doi.org/10.15504/fmj.2018.32

Received: 2018-06-05 / Published: 2018-09-28

\section{Keywords}

Meuse, river, physicochemical

\section{Short description of the dataset/summary}

Three sites, covering the Begium Meuse River had been homogeneously monitored for a longest period of time (1972-2010). Dissolved oxygen, water temperature, suspended matter, nitrates, ammonium, dissolved reactive phosphorus, chlorophyll-a and water discharge were measured by public institutions. For each site and each parameter, annual average values were calculated (mean, min and max).

Fish and invertebrate data of the River Meuse are also available as separate datasets.

\section{General information}

dataset entry ID:

name of the dataset:

full name of the dataset:

dataset short name:

type of dataset:

data type:

\section{SF_3}

Physicochemical data of the Belgian River Meuse from 1972 to 2010

Meuse River physicochemical dataset

environmental characteristics database

point data/observation data

science keywords according to GCMD:

topic:

Climate Indicators, Terrestrial Hydrosphere

ISO topic category according to ISO 19115:

Environment 


\section{INSPIRE keywords according to GEMET:}

Environmental monitoring facilities, Habitats and biotopes

own science keywords:

physico-chemical, long-term measurements, River Meuse, global warming, chlorophyll-a decrease

related project:

Planctonic resources decrease, and habitat alterations, which consequences for the functioning of communities? University of Namur

funding:

We would like to thank the SPW (Belgium) for providing the data corresponding to their Meuse River monitoring programs. This work was funded by the University of Namur.

\section{Technical and administrative specifications}

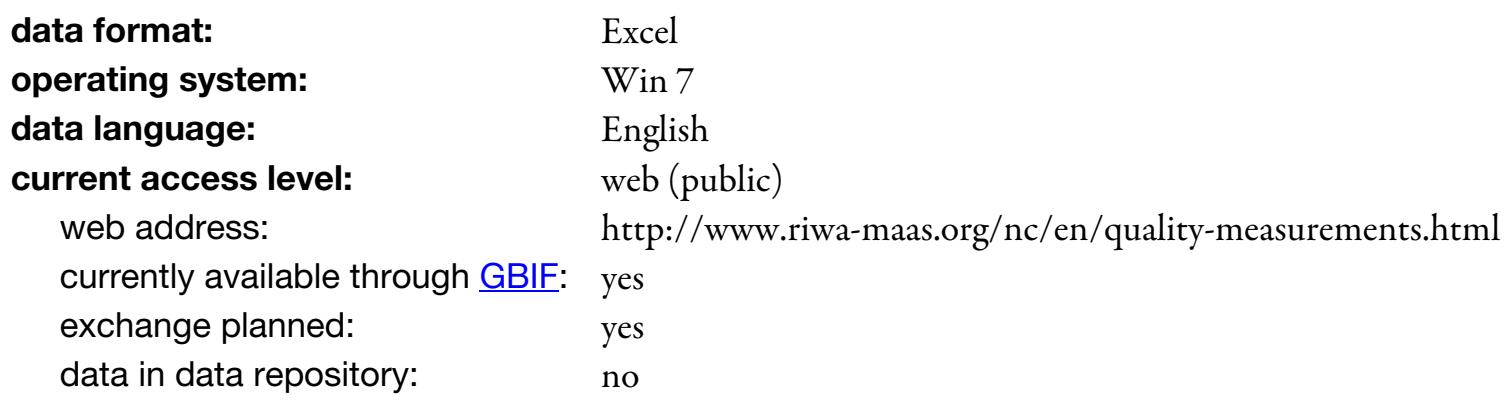

Do you plan to publish the data on the Freshwater Biodiversity Data Portal:

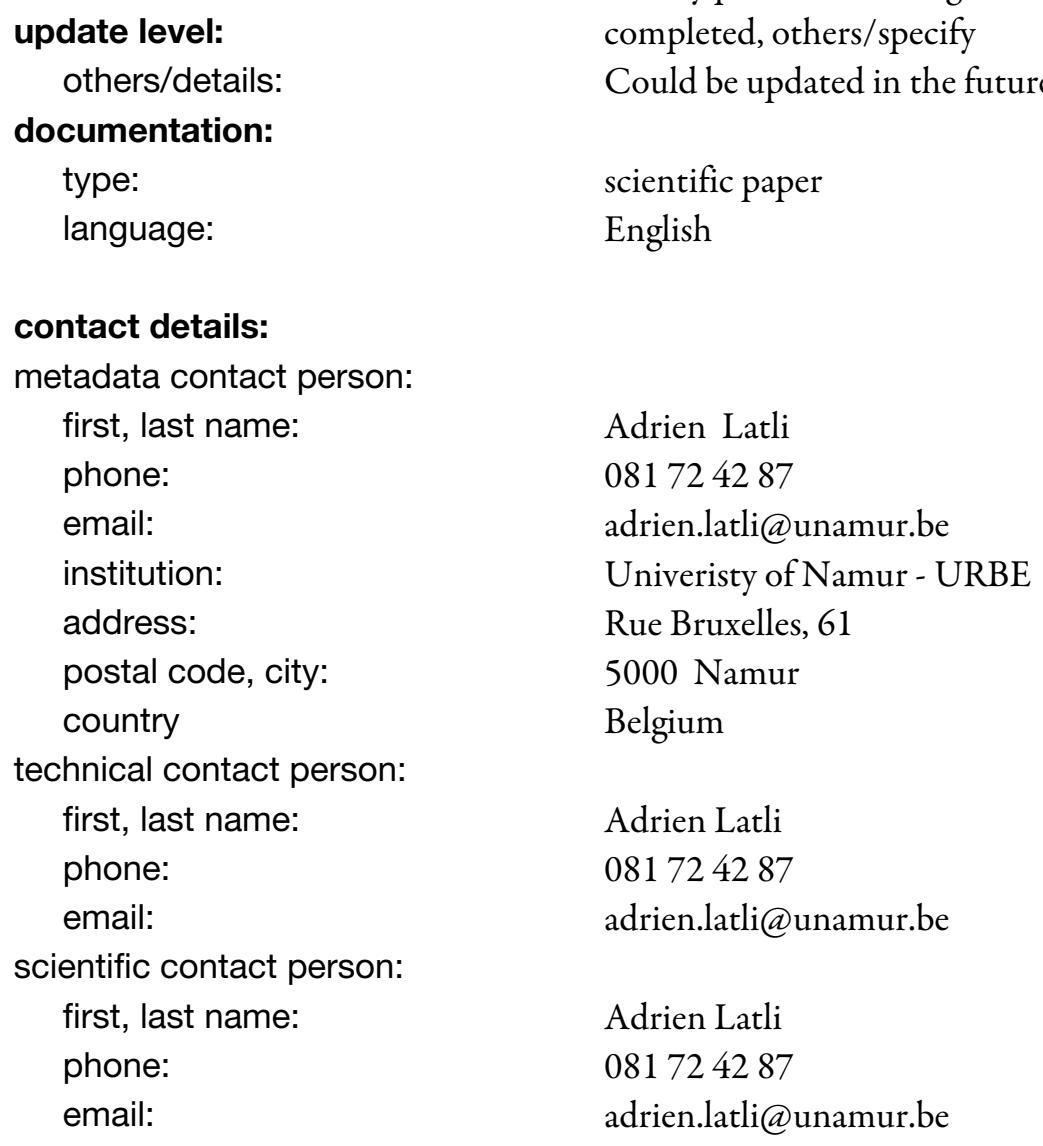




\section{Intellectual property rights and citation}

dataset creator (data compiler):

contact name:

Latli Adrien

contact email:

adrien.latli@unamur.be; patrick.kestemont@unamur.be

contact institution:

University of Namur

data contributors to/owners of this dataset:

multiple

number:

3

data contributor/owner 1:

contact name:

SPW-DGARNE

contact email:

dgarne@spw.wallonie.be

contact institute:

SPW-DGARNE

criteria for using this part of the dataset:

The dataset needs to be requested from dataset creator with specific conditions of use.

data contributor/owner 2:

contact name:

RIWA

contact email:

contact institute:

vanhoutem@riwa.org

RIWA

criteria for using this part of the dataset:

The dataset is publicly available (data portal, data archive) and can be used without restrictions, but must be acknowledged and cited correctly.

other/additional criteria:

http://www.riwa-maas.org/nc/en/quality-measurements.html

data contributor/owner 3:

contact name:

CIM-Meuse

contact email:

secr@meuse-maas.be

contact institute:

CIM-Meuse

criteria for using this part of the dataset:

The dataset needs to be requested from dataset creator with specific conditions of use.

citation of this dataset:

author(s):

Latli, A., Service Public de Wallonie - DG03, RIWA-Maas, CIM-Meuse title and journal (name, number, pages):

Physicochemical evolution of the Belgian River Meuse from 1972 to 2010.

year:

2017

doi:

https://doi.org/10.13148/evwxv1

citation of the metadata:

author(s):

Latli A., Service Public de Wallonie , Kestemont P., RIWA \& CIM-Meuse title and journal (name, number, pages):

Physicochemical data of the Belgian River Meuse from 1972 to 2010. Freshwater Metadata Journal 32: 1-5

year:

2018

doi:

https://doi.org/10.15504/fmj.2018.32

dataset related references:

reference 1:

author(s):

Latli, A., Descy, J.-P., Mondy, C., Floury, M., Viroux, L., Otjacques, W., Marescaux, J., Depiereux, E., Ovidio, M., Usseglio-Polatera, P. \& Kestemont, P.

title: Long-term trends in trait-structure of riverine communities facing predation risk increase and trophic resource decline. Ecological Applications 27(8):

2458-2474. 

year:
2017
doi:
https://doi.org/10.1002/eap.1621

\section{General data specifications}

regional coverage of the dataset:

spatial extent of the dataset: regional

continents: Europe

spatial extent (bounding coordinates):
southernmost latitude $\left[{ }^{\circ}\right]$ :
$4^{\circ} 52^{\prime} 54.7^{\prime \prime}$
northernmost latitude $\left[^{\circ}\right]$ :
$5^{\circ} 34^{\prime} 40.1^{\prime \prime}$
westernmost longitude $\left[^{\circ}\right]$ :
$50^{\circ} 23^{\prime} 52.5^{\prime \prime}$
easternmost longitude [ $\left.{ }^{\circ}\right]$ :
$50^{\circ} 37^{\prime} 53.9$
minimum altitude:
57 metres
maximum altitude:
82 metres
countries:
Europe: Belgium

world climatic regions according to Köppen:

Group C: temperate/mesothermal climates

freshwater ecoregions of the world (FEOW) according to WWF:

Europe: Central \& Western Europe

European ecoregions according to Illies (WFD):

ecosystem type:

covered timeframe:

Western Plains (ER13)

rivers

$1972-2010$

\section{Site specifications}

coordinate system/grid data:

datum (e.g. WGS84):

grid data available:

site coding available:

number of sites:

exact number of sites: latitude/longitude, format: DMS

projected, UTM

WGS84

no

no

$<100$

3

\section{Climate and environmental data}

climate related data:

available parameters per site:

environmental data:

mean annual temperature January, July

data source: https://doi.org/10.1002/eap.1621

mean discharge

data source: https://doi.org/10.1002/eap.1621

available parameters per catchment:

\section{catchment size}

data source: https://doi.org/10.1002/eap.1621

hydrological regime/flow regime 
data source: https://doi.org/10.1002/eap.1621

available parameters per site: river length

data source: https://doi.org/10.1002/eap.1621

distance to source

data source: https://doi.org/10.1002/eap.1621 slope

data source: https://doi.org/10.1002/eap.1621

altitude

data source: https://doi.org/10.1002/eap.1621

discharge

data source: https://doi.org/10.1002/eap.1621

comments:

Latli, A., Descy, J.-P., Mondy, C., Floury, M., Viroux, L., Otjacques, W.,

Marescaux, J., Depiereux, E., Ovidio, M., Usseglio-Polatera, P. \& Kestemont, P. (2017): Long-term trends in trait-structure of riverine communities facing predation risk increase and trophic resource decline. Ecological Applications 27(8): 2458-2474.

physico-chemical data: ortho $\mathrm{P}$, nitrate, ammonium, water temperature, chlorophyll, suspended solids availability of physico-chemical data, if there is more than one sample per site:

stressors influencing the sites: per sample no stressor data available

\section{Other specifications}

\section{GIS layers, shape files related to the dataset:}

$\begin{array}{ll}\text { availability of photos: } & \text { no } \\ \text { availability of maps: } & \text { no } \\ \text { quality control procedures: } & \end{array}$

no data available

no

no

Were any quality control procedures applied to your dataset?

yes

quality control protocols and comments:

We performed a number of systematic checks using the OpenRefine software.

\section{Acknowledgements}

The authors acknowledge the Belgian Science Policy (Belspo) for funding the SAFRED project (Saving freshwater biodiversity research data - 2015-2018) that allowed processing and publishing the data.

\section{References}

Latli, A., Descy, J.-P., Mondy, C., Floury, M., Viroux, L., Otjacques, W., Marescaux, J., Depiereux, E., Ovidio, M., Usseglio-Polatera, P. \& Kestemont, P., 2017. Long-term trends in trait-structure of riverine communities facing predation risk increase and trophic resource decline. Ecological Applications 27(8): 2458-2474. https://doi.org/10.1002/eap.1621 